\title{
MJN ACCURACY OF ALLEN SCORE IN PREDICTING STROKE TYPE
}

\author{
Berna Detha Meilyana*, Sri Andarini, Yati Sri Hayati \\ Brawijaya University, Medical Faculty, Malang, Indonesia \\ *Corresponding Author's Email: dethabenedict@gmail.com; bernadethameily@student.ub.ac.id
}

\begin{abstract}
Background: Stroke is an emergency condition that can cause a decrease in nerve function that is affected by injuries to the central nervous system. The initial examination is needed by nurses to find out the type of stroke that can determine the right treatment and quickly. Determination of the type of stroke is done by using a CT scan tool that has limited facilities in some hospitals, so we need a tool in the form of a stroke scoring that can be used. Aim: This study aims to determine the accuracy of Allen's score in predicting the type of stroke in patients. Methods: This study uses an observational analytic method with a cross-sectional design. The sample selection uses purposive sampling with the number of respondents as many as 100 stroke patients. Observations were made using the Allen score. Results: The results showed 100 patients. Demographic characteristics of patients who have the most strokes are men, the age group that has the most strokes is 54-64 years, working privately. The sensitivity, specificity, NPP, NPN, and accuracy of Allen scores were $98.6 \%$, $100 \%, 100 \%, 96 \%$, and $99.0 \%$ in predicting the type of ischemic stroke. Whereas in predicting the type of hemorrhagic stroke, sensitivity, specificity, NPP, NPN, and accuracy are 83.3\%, 92.6\%, 71.4\%, 96.2\%, and 91\%. Conclusion: Determining the type of stroke quickly and precisely, help is needed by using stroke scoring that can be done by nurses as a basis of providing collaborative care in patient management.
\end{abstract}

Keywords: Allen Stroke Score; Sensitivity and Specificity Allen Score; Stroke; Scoring Stroke

\section{INTRODUCTION}

Cerebrovascular Accident (CVA) or stroke is a clinical emergency condition that can be characterized by a decrease in nerve function, so that patients can not do daily activities (Sacco et al., 2013). Stroke can be divided into two based on the cause, namely hemorrhagic and ischemic stroke. Ischemic stroke is caused by interruption of blood supply to the brain, due to the narrowing or blockage in the form of clots or emboli in the arteries leading to the brain. Hemorrhagic stroke is caused by the rupture of blood vessels of the brain because blood pressure is too high (An, Kim, \& Yoon, 2017).

The prevalence of stroke in the world according to Feigin et al. (2015) as many as 6.5 million caused death and 25.7 million sufferers who experience physical disability due to limb weakness. Data according to research conducted by Putri, Islam, \& Subadi (2018) shows that in Southeast Asia the largest stroke incidence is in Indonesia. The prevalence of stroke in Indonesia increased from 8.3 to 12.1 per 1000 population in 2013 (Putri et al., 2018).
Stroke management in patients can be carried out starting from the initial examination and diagnostic assessment precisely, quickly, and carefully (Middleton, Grimley \& Alexandrov, 2015). Preliminary examination quickly and precisely has a very big influence on the worsening conditions that occur in patients. Standard checks that can be performed using a computerized brain scanning tool (CT scan). However, CT-Scan is not available in all hospitals, other than that it is influenced by expensive costs so that it can affect the treatment time in stroke patients (Amjad et al., 2015, Nadeem, Mustafvi, $\&$ Baqai, 2015). The existence of these obstacles is a very necessary diagnostic tool such as scoring that can distinguish between ischemic and hemorrhagic stroke. One of the scorings that can be used to help determine the type of stroke is the Allen score (Nilanont et al., 2010).

Allen Score or the Guys Hospital Score can be called a stroke scoring tool that can be used to help determine the type of stroke if CT-Scan tools are not available (Sherin et al., 2011). This research was conducted to determine the sensitivity, specificity, and accuracy of the Allen score in helping determine the type of stroke. 


\section{METHODOLOGY}

\section{Study Design}

This study uses an analytical observational research design with a design cross-sectional.

\section{Settings and Respondent}

This research was conducted from March to April 2020 in the Emergency Department (ED). The study population was stroke patients who came to the emergency room with the calculation of the number of samples using the Slovin formula of 100 patients. Sample selection uses purposive sampling with sample inclusion criteria, namely: 1) patients or families willing to be respondents, 2) patients who have had a stroke. The patient exclusion criteria were: 1) the patient refused to be a respondent and 2) the patient was referred.

\section{The Instrument and Measurement}

This research was conducted by observing using the Allen scoring (ASS) standard scoring sheet consisting of 8 indicators namely apoplectic onset, level of consciousness, plantar responses, diastolic blood pressure 24 hours after admission, atheroma markers, history of hypertension, previous events and heart disease. The observation was carried out when the patient entered.

\section{Procedures}

All patients who met the criteria of the study sample and were respondents will be observed. Assessment is done when the patient enters the emergency room by observing the patient's condition and making an assessment on the Allen scoring sheet.

\section{Data Analysis}

Analysis of research data using SPSS version 18.0 with descriptive statistical tests and ROC curves.

\section{Ethical Consideration}

This research has been tested by ethical clearance from the Health Research Ethics Committee of the Faculty of Medicine, Universitas Brawijaya with number: No.59 / EC / KEPK - S2 / 03/2020.

\section{RESULTS}

Table 1 shows the characteristics of the age group respondents who experienced the most strokes were age 54 - 64 years as many as $58 \%$, based on the most sex were male as much as $67 \%$, working privately as much as $42 \%$.
Table 1: Characteristics of Respondents $(n=100)$

\begin{tabular}{|l|c|}
\hline Characteristics & Results \\
\hline Age & $3(3 \%)$ \\
\hline 43 - 53 years & $58(58 \%)$ \\
\hline $54-64$ years old & $34(33.3 \%)$ \\
\hline $65-75$ years old & $5(4.9 \%)$ \\
\hline$>75$ years old & $67(67 \%)$ \\
\hline Gender & $33(33 \%)$ \\
\hline Male & \\
\hline Girl & $32(32 \%)$ \\
\hline Profession & $42(42 \%)$ \\
\hline Does not work & $22(22 \%)$ \\
\hline Private & $4(4 \%)$ \\
\hline Entrepreneur & \\
\hline PNS / TNI / POLRI & \\
\hline
\end{tabular}

Table 2: Frequency Distribution of Respondents Based on Allen's Score

\begin{tabular}{|l|c|c|}
\hline Indicator & Classification & Frequency (n) \\
\hline Apoplectic attack & $\begin{array}{c}\text { None or either } \\
\text { Two or more }\end{array}$ & $80(80.4 \%)$ \\
Level of & Aware & $20(19.6 \%)$ \\
Consciousness & Apathetic & $59(58.4 \%)$ \\
& Coma & $14(13.9 \%)$ \\
\hline Plantar & Both flexion or one & $95(95.0 \%)$ \\
Response & extension & $5(5 \%)$ \\
\hline Diastolic Blood & Both are extensions & $60(60 \%)$ \\
Pressure & $\geq 100$ & $40(40 \%)$ \\
\hline Atheroma & There is no & $21(20.6 \%)$ \\
Marker & One or more & $81(79.4 \%)$ \\
\hline History of & Do not have & $18(18 \%)$ \\
Hypertension & Have any & $82(82 \%)$ \\
\hline CVA / TIA history & Never & $48(48.0 \%)$ \\
& Two or more & $52(52.0 \%)$ \\
\hline History of Heart & There is no & $83(83 \%)$ \\
Disease & There is & $17(17 \%)$ \\
\hline
\end{tabular}

The results of observations using Allen's scoring are apoplectic attacks experienced by respondents as much as $80.4 \%$, awareness levels with as many as $58.4 \%$ of respondents are aware, 95\% plantar responses experience both flexions, diastolic blood pressure $\leq 100$ by $60 \%$. Hypertension as much as $82 \%$. CVA history of $52 \%$ and a history of heart disease by $17 \%$. 
Table 3: Frequency Distribution of Allen's Score Results

\begin{tabular}{|l|c|c|}
\hline Scoring Allen & $\begin{array}{c}\text { Frequency } \\
(\mathbf{n})\end{array}$ & $\begin{array}{c}\text { Percentage } \\
(\mathbf{\%})\end{array}$ \\
\hline Ischemic & 75 & 75 \\
\hline Vague & 17 & 17 \\
\hline Hemorrhagic & 8 & 8 \\
\hline Total & 102 & 100 \\
\hline
\end{tabular}

The frequency distribution results that $75 \%$ are included in the ischemic classification, while $8 \%$ are included in the hemorrhagic classification and $17 \%$ is included in the vague classification.

Table 4: Predicting Cerebral Haemorrhage with Allen Score

\begin{tabular}{|l|l|c|c|}
\hline Predicting & & \multicolumn{2}{|c|}{ Result } \\
\cline { 3 - 4 } $\begin{array}{l}\text { Stroke } \\
\text { Subtypes with }\end{array}$ & $\begin{array}{c}\text { Cerebral } \\
\text { Hemorrhage }\end{array}$ & $\begin{array}{c}\text { Not Cerebral } \\
\text { Hemorrhage }\end{array}$ \\
\cline { 2 - 4 } & $\begin{array}{l}\text { Cerebral Score } \\
\text { Hemorrhage }\end{array}$ & 15 & 6 \\
\cline { 2 - 4 } & $\begin{array}{l}\text { Not Cerebral } \\
\text { Hemorrhage }\end{array}$ & 3 & 76 \\
\hline
\end{tabular}

Table 5: Predicting Cerebral Ischemic with Allen Score

\begin{tabular}{|c|c|c|c|}
\hline \multirow{2}{*}{$\begin{array}{l}\text { Predicting } \\
\text { Stroke } \\
\text { Subtypes with } \\
\text { Allen Score }\end{array}$} & & \multicolumn{2}{|c|}{ Result } \\
\hline & & $\begin{array}{l}\text { Cerebral } \\
\text { Ischemic }\end{array}$ & $\begin{array}{l}\text { Not Cerebral } \\
\text { Ischemic }\end{array}$ \\
\hline Allen Score & $\begin{array}{l}\text { Cerebral } \\
\text { Ischemic }\end{array}$ & 75 & 0 \\
\hline & $\begin{array}{l}\text { Not Cerebral } \\
\text { Ischemic }\end{array}$ & 1 & 24 \\
\hline
\end{tabular}

ROC curve analysis is performed to determine the AUC value, cut off point, sensitivity, specificity, positive predictive value, negative predictive value, and accuracy. Area Under Curve (AUC) value of receiver Operating Characteristic(ROC) is calculated based on the results of the stroke scoring. Table 5 explains the AUC values obtained when analyzing the results of the Allen score to determine both ischemic and hemorrhagic strokes. The ROC curve can be seen in the figure as follows.

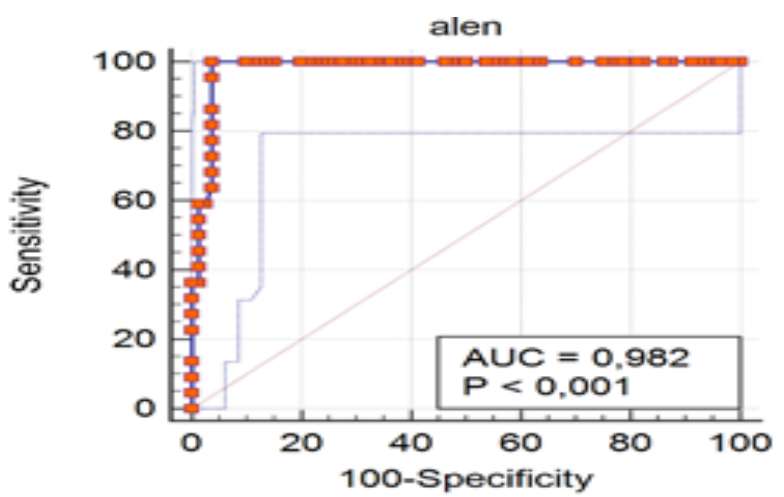

Figure 1: ROC curve Predicting Haemorrhage with Allen Score

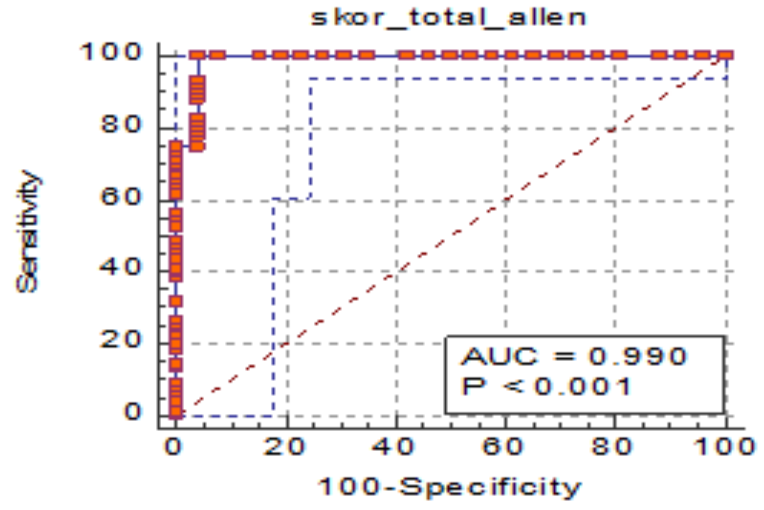

Figure 2: ROC Curve Predicting Ischemic with Allen Score

Table 5: ROC Curve Analysis Allen Score Stroke

\begin{tabular}{|l|c|c|c|}
\hline Scoring & $\begin{array}{c}\text { AUC } \\
\text { (standard } \\
\text { error) }\end{array}$ & $\begin{array}{c}\text { Optimal } \\
\text { cut-off }\end{array}$ & $\begin{array}{c}\mathbf{9 5 \%} \\
\text { Confidence } \\
\text { interval }\end{array}$ \\
\hline $\begin{array}{l}\text { Allen } \\
\text { scores } \\
\text { predicting } \\
\text { hemorrhage }\end{array}$ & $0.983(0.108)$ & $>3$ & $0.934-0.998$ \\
\hline $\begin{array}{l}\text { Allen's } \\
\text { score } \\
\text { predicting } \\
\text { ischemic }\end{array}$ & $0.990(0.103)$ & $<3$ & $0.945-1.000$ \\
\hline
\end{tabular}

\section{DISCUSSION}

Stroke has a large impact on the quality of life of patients, where most stroke patients experience decreased function of the motion due to neurological disorders, so patients can not do daily activities (Rahman \& Jamal, 2015). Disturbances in brain function cause symptoms to appear and last for 6 to 24 hours from the onset of events (Goswami, Karmakar \& Ghosh, 2013).

Stroke management is given to stroke patients starting from the initial examination by using stroke scoring which can be done easily, quickly, and efficiently to predict the type of ischemic or hemorrhagic stroke. Clinical assessment of stroke can help in determining the diagnosis in hospitals with limited CT-Scan aids Gaire et al., 2015. Allen's score has a high accuracy value to predict the type of stroke. The accuracy value can be seen from the sensitivity, specificity, positive predictive value, and negative predictive value(Sherin et al., 2011). This study is a trial conducted at a hospital that has not been available with a $\mathrm{CT}$ scan and the existence of a low economic influence, 
so that examination in stroke patients is not optimal.

Demographic data of the results of the study showed that male respondents with several $67 \%$ had a stroke. Factors that cause high strokes are more common in men than women because men have a smoking habit and have a history of consuming alcohol, this can trigger the chance of a stroke(Girijala, Sohrabji \& Bush, 2016).

The age range of stroke in this study is more common in 54 - 64 years which is equal to $58 \%$. Research from (Choudhury et al., 2015) states that age has been identified as a marker of stroke risk that cannot be modified, the greatest risk of stroke ranging from ages 55-64 years.

The results showed as many as $82 \%$ had a history of hypertension and diastolic blood pressure $<100$ as much as $60 \%$. Diastolic and systolic blood pressure also have a major influence on stroke risk factors. Uncontrolled hypertension will cause thickening of the arteries, so hypertension can cause blood vessels to rupture or blood vessels to constrict (Raghuram, Biradar \& Jeganathan, 2012). Based on research that has been done it is seen that hypertension has a close continuity with cardiovascular disease and diabetes mellitus in stroke patients, even the risk of stroke will increase when hypertension is associated with other risk factors (Legge et al., 2012). Cardiovascular risk factors in this study were $17 \%$. Heart disease that is often atrial fibrillation $(\mathrm{AF})$ heart failure $(\mathrm{HF})$ or often called heart failure has increased the prevalence of stroke(Gibson, 2013). The results showed a history of diabetes mellitus in patients at $79.4 \%$.

The results of research that have been done show that Allen's score has the accuracy to help predict the type of ischemic or hemorrhagic stroke. The results showed that the Allen score for predicting ischemic stroke had a sensitivity value of $98.6 \%$, specificity $100 \%$, Positive Prediction Value (NPP)100\%, Negative Prediction Value (NPN) 96\%, and accuracy 99\%. The results of this study are in line with those conducted by Raghuram et al., (2012) that shows the results on the Allen score to predict the type of ischemic stroke obtained a sensitivity value of $95 \%$, the specificity of $80 \%$, Predictive Positive Value (PPV) 93\%. Subsequent clinical studies were carried out by HYPERLINK $\backslash 1$ "_ENREF_13" \o "Pandey R P, 2019 \#69" Pandey, Pandey \& Indurkar, M. (2015) (2019) on 100 patients who came to the hospital with signs and symptoms of stroke. Stroke examination and observation were performed using Allen's stroke score. hospital with signs and symptoms of stroke, stroke examination and observation were performed using Allen's stroke score. This study shows that Allen's score shows good sensitivity and positive predictive values $(96.2 \%$ and $91.22 \%$ ) for the assessment of ischemic stroke types.

Research which is conducted by (Goswami et al., 2013) the results obtained Allen scores sensitivity of $63.38 \%$, the specificity of $95.35 \%$, Predictive Positive Value (PPV) $13.62 \%$ and Negative Predictive Value (NPV) of $38 \%$, these results have a lower value comparison in predicting ischemic stroke.

In our study, hemorrhagic stroke was obtained a Sensitivity value of $83.3 \%$, Specificity of $92.6 \%$, Positive Prediction Value (PPV)71.4\%, Negative Prediction Value (NPV) $96.2 \%$ and accuracy 91\%. Research conducted (Connor et al., 2016), showed that the Allen score had a sensitivity value of $34 \%$, the specificity of 95\%, Predictive Positive Value (PPV) $77 \%$. In predicting hemorrhagic stroke. Other studies conducted by(Sherin et al., 2011) states that the results of the Allen score assessment have a value sensitivity of $38.70 \%$, specificity of $91.30 \%$, Predictive Positive Value (PPV) $66.67 \%$ and Negative Predictive Value (NPV) $76.82 \%$.

Analysis of the results of several studies that have been conducted can be concluded that the Allen score has a higher value in helping predict the type of ischemic stroke. However, the results of this score are influenced by the conditions, signs, and symptoms experienced by the patient. Stroke scores can be said to be ideal for determining the type of stroke that must have a good balance between validity, simplicity, and function (Goswami, Karmakar \& Ghosh, 2013). This stroke score assessment becomes an important tool and function in helping diagnose and provide care given to patients. Besides determining the type of stroke is very useful for the prevention of recurrent stroke (Arsava et al., 2017).

\section{CONCLUSION}

Determining the type of stroke quickly and precisely, help is needed by using scoring that can be done by nurses as a basis for providing collaborative care inpatient management. Allen's Score is a simple scoring aid that can help nurses in conducting initial 
examinations in determining the type of ischemic or hemorrhagic stroke in hospitals that have limited assistive facilities such as CT - Scan.

\section{Conflict of Interests}

The authors declare that they have no conflict of interest

\section{ACKNOWLEDGMENT}

Special thanks and gratitude are offered to the medical staff and patients in oncology department at Al Fardose Clinic in health insurance, Mansoura, Egypt., Egypt for their cooperation and support during conducting this study.

\section{REFERENCES}

Amjad, Z., Nadeem, M., Mustafvi, S. A. \& Baqai, H. Z. (2015). Accuracy of Siriraj Stroke Score in Ascertaining the Type of Stroke. Journal of Islamabad Medical \& Dental College (JIMDC), 4(4), pp 167-170.

An, S. J., Kim, T. J. \& Yoon, B.W. (2017). Epidemiology, risk factors, and clinical features of intracerebral hemorrhage: an update. Journal of Stroke, 19(1), p 3.

Arsava, E. M., Helenius, J., Avery, R., Sorgun, M. H., Kim, G. M., Pontes-Neto, O. M. ... \& Ay, H. (2017). Assessment of the predictive validity of etiologic stroke classification. JAMA Neurology, 74(4), pp 419-426.

Choudhury, M. S., Chowdhury, M. D., Nayeem, Abu, \& Jahan, Waseka. (2015). Modifiable and Non-Modifiable Risk Factors of Stroke: A Review Update. Journal of the National Institute of Neurosciences Bangladesh, 1, 22.

Connor, M. D., Modi, G. \& Warlow, C. P. (2007). Accuracy of the Siriraj and Guy's hospital stroke scores in urban South Africans. Stroke, 38(1), 62-68.

Di Legge, S., Koch, G., Diomedi, M., Stanzione, P. \& Sallustio, F. (2012). Stroke prevention: managing modifiable risk factors. Stroke Research and Treatment, 2012.

Feigin, V. L., Krishnamurthi, R. V., Parmar, P., Norrving, B., Mensah, G. A., Bennett, D. A. \& Roth, G. A. (2015). Update on the global burden of ischemic and hemorrhagic stroke in 1990-2013: the GBD 2013 study. Neuroepidemiology, 45(3), 161-176.

Gaire, D., AD, P. A. R., Rana, K. J. \& Karki, L. (2015). Stroke Scoring??? Does it have role. Post-Graduate Medical Journal of NAMS, 12(01).

Gibson, C. L. (2013). Cerebral ischemic stroke: is gender important?. Journal of Cerebral Blood Flow \& Metabolism, 33(9), pp 1355-1361.

Girijala, R. L., Sohrabji, F. \& Bush, R. L. (2017). Sex differences in stroke: review of current knowledge and evidence. Vascular Medicine, 22(2), pp 135-145.

Goswami, R., Karmakar, P. \& Ghosh, A. (2013). Bedside utility of clinical scoring systems in classifying stroke. Indian Journal of Medical Sciences, 67(5/6), 137.

Middleton, S., Grimley, R. \& Alexandrov, A. W. (2015). Triage, treatment, and transfer: evidence-based clinical practice recommendations and models of nursing care for the first 72 hours of admission to hospital for acute stroke. Stroke, 46(2), e18-25.

Nilanont, Y., Komoltri, C., Saposnik, G., Côté, R., Di Legge, S., Jin, Y., Prayoonwiwat, N., Poungvarin, N. \& Hachinski, V. (2010). The Canadian Neurological Scale and the NIHSS: development and validation of a simple conversion model. Cerebrovascular Diseases, 30(2), pp 120-126.

Putri, N. N., Islam, M. S. \& Subadi, I. (2018). Comparison of Acute Ischemic Stroke Functional Outcome in Smokers and Nonsmokers Measured By Canadian Neurological Scale (CNS) and NIHSS. Malang Neurology Journal, 4(2), 
pp 65-71.

Raghuram, P., Biradar, M.S. \& Jeganathan, J. (2012). Comparison of the Siriraj Stroke Score and the Guy's Hospital Score in South India. Journal of Clinical \& Diagnostic Research, 6(5).

Rahman, A. \& Jamal, Q. (2015). Comparison of Siriraj Stroke Score With Computerized Tomography in Establishing the Type of the StrokeAmong Pakistani Population (P1.078).

Sacco, R.L., Kasner, S.E., Broderick, J.P., Caplan, L.R., Connors, J.J., Culebras, A., Elkind, M.S., George, M.G., Hamdan, A.D., Higashida, R.T. \& Hoh, B.L. (2013). An updated definition of stroke for the $21^{\text {st }}$ century: a statement for healthcare professionals from the American Heart Association/American Stroke Association. Stroke, 44(7), pp 2064-2089.

Sherin, A., Khan, A., Rehman, S., Shah, N. H., Shabbier, G. \& Zarif, M. (2011). Comparability and validity of Siriraj stroke score and Allen stroke score in differentiation of acute ischemic and haemorrhagic stroke. Journal of Postgraduate Medical Institute (Peshawar-Pakistan), 25(3). 